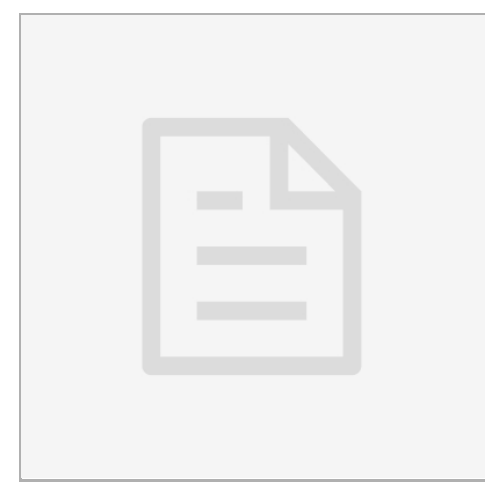

\title{
(3) Two-minute walk test: reference equations for healthy adults and the elderly in China
}

He $\mathrm{Zou}^{1}$

${ }^{1}$ Wenzhou Medical College

re zod

He Zou

\section{JUN 09, 2018}

\section{open ठaccess}

\section{DOI:}

dx.doi.org/10.17504/protocol s. io.quqdwrw

\section{Protocol Citation: He Zou}

2018. Two-minute walk test: reference equations for healthy adults and the elderly in China. protocols.io https://dx.doi.org/10.17504/p rotocols.io.quqdwvw

\section{License: This is an open} access protocol distributed under the terms of the Creative Commons Attribution License, which permits unrestricted use, distribution, and reproduction in any medium, provided the original author and source are credited

Protocol status: Working We use this protocol and it's working

Created: Jun 09, 2018

Last Modified: Jun 09, 2018

\section{PROTOCOL integer ID:}

\section{2}

\section{Location}

1 The two-minute walk test (2MWT) should be performed indoors, along a long, flat, straight, enclosed corridor with a hard surface that is seldom traveled. If the weather is comfortable, the 
test may be performed outdoors. The walking course must be $30 \mathrm{~m}$ in length.

\section{Required equipmemt}

2

(1). Countdown timer (or stopwatch)

(2). Mechanical lap counter

(3). Two small cones to mark the turnaround points

(4). A chair that can be easily moved along the walking course

(5). Worksheets on a clipboard

(6). A oximeter

(7). Sphygmomanometer

(8). Telephone

\section{Subject preparation}

3 1. Comfortable clothing should be worn.

2. Appropriate shoes for walking should be worn.

3. A light meal is acceptable before early morning or early afternoon tests.

4. Subjects should not have exercised vigorously within 2 hours of beginning the test.

\section{Measurements}

4 1. Repeat testing should be performed about the same time of day to minimize intraday variability.

2. A "warm-up" period before the test should not be performed.

3. The subject should sit at rest in a chair, located near the starting position, for at least 10 minutes before the test starts. During this time, check for contraindications, measure pulse and blood pressure, and make sure that clothing and shoes are appropriate.

4. Position the subject at the starting line. You should also stand near the starting line during the test. Each subject was asked to walk up and down the corridor as fast as possible in two minutes. As soon as the subject starts to walk, start the timer.

5. The operator needed to prompted the subjects after 60 seconds using standardized encouragement ('you are doing well; you have one minutes left').

6.Record the number of laps from the counter (or tick marks on the worksheet).

7. Record the additional distance covered (the number of meters in the final partial lap) using the markers on the wall as distance guides. Calculate the total distance walked, rounding to the nearest meter, and record it on the worksheet.

8. Congratulate the subject on good effort and offer a drink of water. 